\title{
UJI TOKSISITI ASAM $\alpha$-LINOLENIK RUMPUT LAUT Ulva sp. TERHADAP Chattonella marina DAN Heterosigma akashiwo
}

\section{TOXICITY ASSAY OF $\alpha$-LINOLENIC ACID FROM Ulva sp. SEAWEED ON Chattonella marina AND Heterosigma akashiwo}

\author{
Moch. Amin Alamsjah \\ Fakultas Perikanan dan Kelautan - Universitas Airlangga \\ Kampus C UNAIR Mulyorejo Surabaya 60115 Telp. 031-5911451 \\ E-mail : alamsjah@unair.ac.id ; alamsjah_70@yahoo.com \\ Telp./Fax. 031-5028709, 5911451
}

\begin{abstract}
The higher toxicity of $\alpha$-linolenic acid from Ulva sp. seaweed showed the high algicidal activity against Chattonella marina and Heterosigma akashiwo. Among six species tested, $C$. marina and $H$. akashiwo was the most susceptible to this fatty acid, whereas $\mathrm{LC}_{50}$ of $\alpha$-linolenic acid was estimated to be 3.22 and $0.58 \mu \mathrm{g} / \mathrm{mL}$, respectively. Furthermore, $\alpha$-linolenic acid also showed algicidal activity against Alexandrium tamarense and A. taylori. It is suggested that $\alpha$-linolenic acid is useful mitigation agents to Harmful Algal Bloom effect, especially on Chattonella marina and Heterosigma akashiwo.
\end{abstract}

Key words : Ulva sp., $\alpha$-linolenic acid, Chattonella marina, Heterosigma akashiwo

\section{Pendahuluan}

Pada tiga dasawarsa terakhir telah banyak eksplorasi penemuan bahan aktif dari organisma maupun substansi laut yang dilakukan (Smit, 2004), seperti halnya eksplorasi bahan aktif rumput laut. Suzuki et al. (1998) telah mengisolasi bahan aktif algicidal dari crustose coralline algae, Lithophyllum spp., terhadap kelulushidupan Harmful Algal Bloom (HAB) Heterosigma akashiwo dan zoospora alga coklat Laminaria religiosa. Perbedaan aktifitas bahan aktif rumput laut dari kelompok PUFA diyakini juga memberikan perbedaan tekanan pertumbuhan Harmful Algal Bloom (HAB) species (Alamsjah et al., 2006). Namun, keberadaan bahan aktif dari jenis rumput laut Ulva sp. belum banyak diketahui terhadap kelulushidupan HAB species sehingga dapat dijadikan dasar pengembangan penggunaan bahan aktif rumput laut Ulva sp. lebih jauh.

\section{Materi dan Metode Penelitian}

Koleksi rumput laut Ulva sp.

Koleksi rumput laut dari intertidal area dikumpulkan selama 3 bulan pertama jangka waktu penelitian. Kerusakan ekologi selama pengambilan sampel diupayakan seminimal mungkin dengan tidak merusak algal stem. Semua sampel di bawa ke laboratorium dalam plastic bag yang mengadung air laut untuk mencegah evaporasi, kemudian mencucinya dengan distilled water untuk memisahkan potential contaminant. Untuk kelayakan penggunaan selanjutnya, sebagian koleksi rumput laut dikeringkan selama 5 hari pada temperatur kamar dan digiling menjadi powder dengan menggunakan blender.

Skreening aktifitas algicidal

Fragment rumput laut diperlakukan dalam methanol dan water ekstraksi berdasarkan metoda Jeong et al. (2000) dengan minor modifikasi. Setiap $100 \mathrm{mg}$ sampel kering di rendam dalam $5 \mathrm{ml}$ methanol pada temperatur kamar selama 24 jam dan di filter melalui filter paper no. 2 (Advantec) dengan tekanan. Prosedur ekstraksi di ulang tiga kali kemudian digabung. Residual tissue dikeringkan dan selanjutnya di ekstraksi dengan distilled water selama 24 jam pada temperatur kamar.

Ekstraksi, isolasi dan struktural determinasi substansi algicidal

Rumput laut terpilih di blender dan di ekstraksi menggunakan methanol. Setelah melepaskan methanol dalam kondisi reduced pressure, selanjutnya residu dipisahkan antara air dan hexane. Hexane extract dikonsentrasikan dan di ekstrak dengan aqueous $\mathrm{HCl}$ dan dilanjutkan $50 \%$ aqueous $\mathrm{MeOH}$. Hexane layer kemudian dikonsentrasikan sehingga meninggalkan deep green oily residue. Tahap berikutnya adalah chromatographi pada silica gel $(63-230 \mu \mathrm{m})$ dan di elusi dengan gradient hexane-EtOAc. Active fraction di kromatografi pada Octadecyl-S $(50 \mu \mathrm{m})$ dan di elusi dengan 
90\% methanol. Kemudian purifikasi HPLC dengan Cosmosil 5C18-MS-II, 20 x $250 \mathrm{~mm}$,

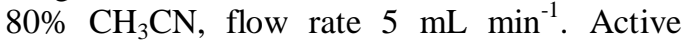
fraction dipurifikasi lagi dengan TLC RP-18 (Merck, $20 \times 20 \mathrm{~cm}$, layer thickness $0.25 \mathrm{~mm}$ ) menggunakan $85 \% \quad \mathrm{CH}_{3} \mathrm{CN}$ sebagai solvent untuk menghasilkan compound akhir. Struktural determinasi substansi algicidal rumput laut terseleksi dilanjutkan dengan menggunakan analisa NMR, MS dan IR spectroscopy.

Toxicity test pada red tide phytoplankton

Red tide phytoplankton species

(Chattonella marina, Heterosigma akashiwo, Alexandrium tamarense, A. taylori, Gymnodinium impudicum dan Heterocapsa circulariscuama) di kultur dalam medium ESM (Erd-Schreiber modified) pada $\mathrm{pH} \mathrm{8,2} \mathrm{dalam}$ kondisi illuminasi $40 \mu \mathrm{mol} / \mathrm{m}^{2} / \mathrm{s}$ dengan 40 watt fluorescent lamps FL40SD (Toshiba) dengan photoperiode 12L : 12D. Semua kultur menggunakan $100 \mathrm{ml}$ Erlenmeyer flask sterilized dengan $50 \mathrm{ml}$ medium. Uji toxicity test pada semua jenis phytoplankton diperlakukan pada 24 well microplate (1 $\mathrm{ml} /$ well) dengan beberapa konsentrasi yang berbeda struktur kimia substansi algicidal rumput laut terseleksi, selama 24 jam. Perhitungan kelulushidupan phytoplankton dilakukan dengan menggunakan haemocytometer.

\section{Hasil dan Pembahasan}

Melalui analisa NMR diperoleh bahan aktif dari rumput laut Ulva sp. adalah asam $\alpha$ linolenik dengan perincian sebagai berikut : NMR $\delta_{\mathrm{H}}\left(400 \mathrm{MHz}, \mathrm{CDCl}_{3}\right): 0,98(\mathrm{t}, 3 \mathrm{H}, J=$ 7,6 Hz, $\left.-\mathrm{CH}_{2} \mathrm{CH}_{3}\right), 1,27-1,37\left(\mathrm{~m}, 8 \mathrm{H},-\mathrm{CH}_{2}-\mathrm{x}\right.$ 4), 1,59-1,67 (m, 2H, - $\left.\mathrm{CH}_{2}-\mathrm{CH}_{2}-\mathrm{COOH}\right), 2,01-$ $2,11\left(\mathrm{~m}, 4 \mathrm{H}, \mathrm{CH}=\mathrm{CH}-\mathrm{CH}_{2}-\mathrm{x} 2\right), 2,35(\mathrm{t}, 2 \mathrm{H}, \mathrm{J}=$ $\left.7,2 \mathrm{~Hz},-\mathrm{CH}_{2}-\mathrm{COOH}\right), 2,77-2,85(\mathrm{~m}, 4 \mathrm{H}$, $\left.\mathrm{CH}=\mathrm{CH}-\mathrm{CH}_{2}-\mathrm{CH}=\mathrm{CH} \times 2\right), 5,28-5,43(\mathrm{~m}, 6 \mathrm{H}$, $\mathrm{CH}=\mathrm{CH}-\mathrm{x} 3$ ), 7.26 (br. s, $1 \mathrm{H},-\mathrm{COOH})$. NMR $\delta_{\mathrm{C}}\left(100 \mathrm{MHz}, \mathrm{CDCl}_{3}\right): 14,3\left(-\mathrm{CH}_{3}\right), 20,6\left(-\mathrm{CH}_{2}-\right.$ $\left.\mathrm{CH}_{3}\right), \quad 24,8 \quad\left(\mathrm{CH}=\mathrm{CH}-\mathrm{CH}_{2}-\mathrm{CH}=\mathrm{CH}\right), \quad 25,6$ $\left(\mathrm{CH}=\mathrm{CH}-\mathrm{CH}_{2}-\mathrm{CH}=\mathrm{CH}\right), 27,2 \quad\left(-\mathrm{CH}_{2}-\mathrm{CH}=\mathrm{CH}\right)$, $29,1\left(-\mathrm{CH}_{2}-\mathrm{CH}_{2} \mathrm{COOH}\right), 29,1 \quad\left(-\mathrm{CH}_{2}-\right), 29,2$ ($\left.\mathrm{CH}_{2^{-}}\right), 29,6\left(-\mathrm{CH}_{2}-\right), 29,7\left(-\mathrm{CH}_{2}-\right), 34,0\left(-\mathrm{CH}_{2}^{-}\right.$ $\mathrm{COOH}), 127,0(-\mathrm{CH}=\mathrm{CH}-), 127,6(-\mathrm{CH}=\mathrm{CH}-)$, $128,1 \quad(-\mathrm{CH}=\mathrm{CH}-), 128,2 \quad(-\mathrm{CH}=\mathrm{CH}-), 130,1 \quad(-$ $\mathrm{CH}=\mathrm{CH}-), 131,9(-\mathrm{CH}=\mathrm{CH}-), 180,6(\mathrm{COOH})$. EIMS $m / z: 278\left(\mathrm{M}^{+}\right.$, base), 228, 222, 108, 95, 79, 75, 67, 55. HRMS $\mathrm{m} / \mathrm{z}\left(\mathrm{M}^{+}\right)$: Perhitungan untuk $\mathrm{C}_{18} \mathrm{H}_{30} \mathrm{O}_{2}: 278,2246$ dan didapatkan 278,2229.

Pengaruh dari $\alpha$-linolenik terhadap raphydophyceae $C$. marina dan $H$. akashiwo menunjukkan hambatan terbesar, dimana berdasarkan nilai $\mathrm{LC}_{50}$ dari $\alpha$-linolenik terhadap C. marina sebesar $3,22 \mu \mathrm{g} / \mathrm{mL}$, sedangkan pengaruh asam $\alpha$-linolenik terhadap $H$. akashiwo sebesar 0,58 $\mu \mathrm{g} / \mathrm{mL}$ (Gambar 1 dan Tabel 1).

Tabel 1. Nilai $\mathrm{LC}_{50}$ dari asam linoleik dan $\alpha$ linolenik terhadap beberapa HAB species dengan lama perlakuan 24 jam

\begin{tabular}{|l|c|}
\hline \multicolumn{1}{|c|}{ Species } & $\begin{array}{c}\mathrm{LC}_{50} \text { asam } \alpha- \\
\text { linolenik } \\
(\mu \mathrm{g} / \mathrm{mL})\end{array}$ \\
\hline Alexandrium tamarense & 66,06 \\
Alexandrium taylori & 35,30 \\
Chattonella marina & 3,22 \\
Heterosigma akashiwo & 0,58 \\
Heterocapsa circularisquama & $>1000$ \\
Gymnodinium impudicum & $>1000$ \\
\hline
\end{tabular}

Kemampuan toksik dari PUFA asam $\alpha$ linolenik di duga berhubungan dengan amphiphatic property yang dimiliki oleh struktur asam lemak tak jenuh, sehingga mengganggu bahkan merusak integritas membran sel red tide phytoplankton species. Struktur kimia dengan perbedaan jumlah dobel karbon asam lemak tak jenuh diamati juga berhubungan dengan aktifitas biologi yang dimilki oleh red tide phytoplankton species $H$. akashiwo. Hasil dalam studi ini sesuai dengan penelitian yang telah dilakukan oleh Suzuki et al. (1996) dan Sellem et al. (2000). Kakisawa et al. (1988) juga melaporkan bahwa PUFA sangat efektif dalam menekan kelulushidupan HAB species yang tidak mengandung dinding sel yang kuat. Ikawa (2004) mencoba menjelaskan tentang pengaruh hambatan yang dimilki PUFA terhadap pertumbuhan phytoplankton dengan cara mempengaruhi lapisan lipid bilayer dari membran sel. Murata et al. (1989) dan Oda et al. (1992) juga melaporkan bahwa aktifitas toksik PUFA kemungkinan disebabkan adanya proses oksidasi, sedangkan Kogteva dan Bezuglov (1998) menyatakan bahwa aktifitas toksik PUFA kemungkinan karena peranannya sebagai second messenger yang mengatur fungsionalisasi aktifitas protein selanjutnya.

Bahan aktif rumput laut Ulva sp. berupa asam $\alpha$-linolenik menunjukkan sebagai substans yang mampu menekan pertumbuhan red tide phytoplankton, selain kelebihan dari komponen asam lemak tak jenuh yang relatif stabil dibandingkan asam lemak jenuh. Sargent et al. (1987) juga melaporkan bahwa penyimpanan kandungan asam lemak jenuh sangat dipengaruhi kondisi lingkungan dan sangat berbeda dengan asam lemak tak jenuh 
yang relatif stabil. Pada akhirnya, biosintesis PUFA asam $\alpha$-linolenik dari Ulva sp. diharapkan dapat dieksplorasi lebih lanjut untuk
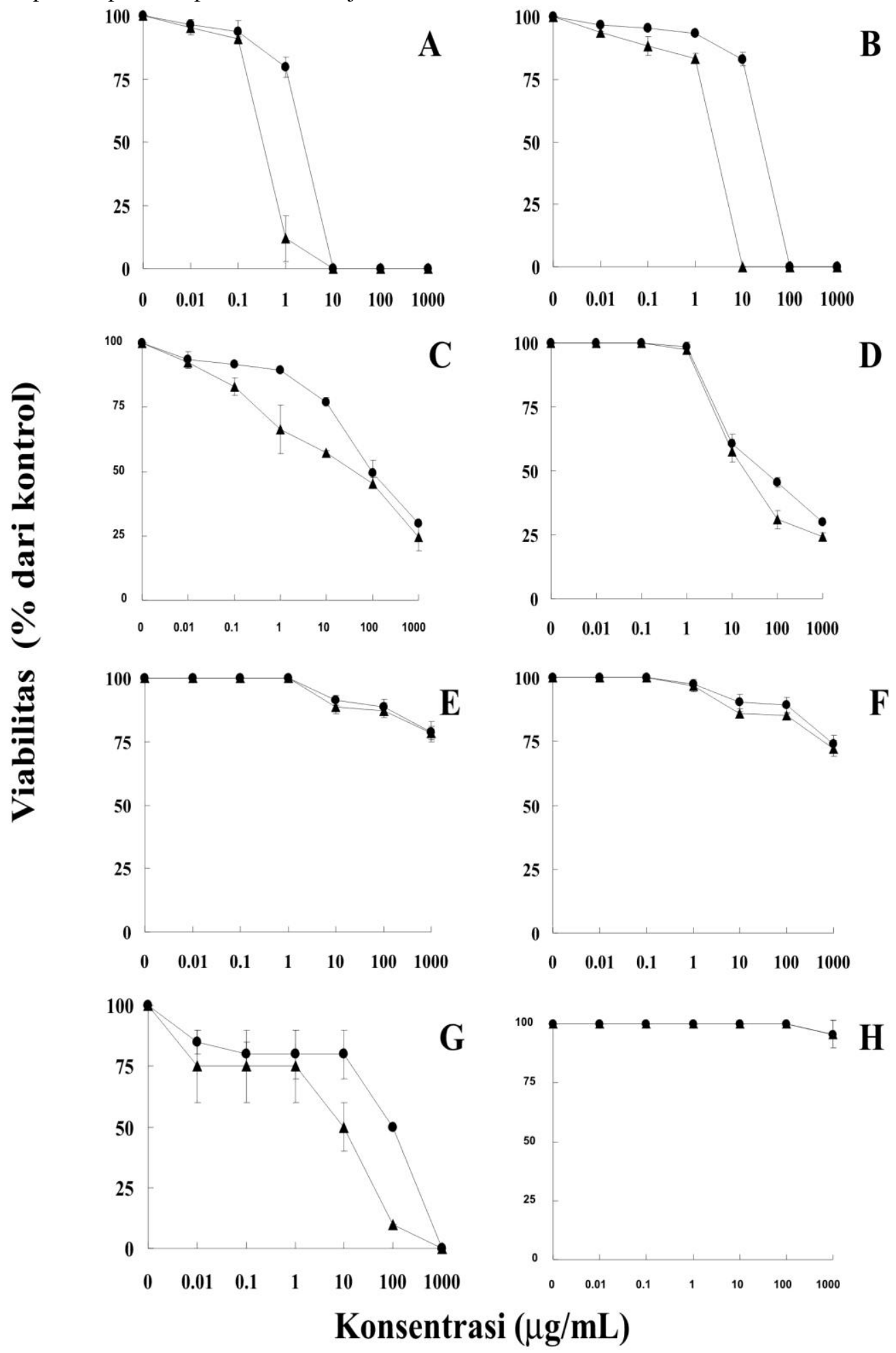

Gambar 1. Efek toksik dari $(\bullet)$ asam linoleik dan $(\boldsymbol{\bullet})$ asam $\alpha$-linolenik terhadap (A) Chattonella marina, (B) Heterosigma akashiwo, (C) Alexandrium tamarense, (D) A. taylori, (E) Gymnodinium impudicum, $(\mathrm{F})$ Heterocapsa circularisquama, $(\mathrm{G})$ Brachionus plicatilis and $(\mathrm{H})$ Artemia sp. Tiap point menunjukkan rata-rata dari tiga kali ulangan dan setiap garis bar menunjukkan besaran SD. 


\section{Kesimpulan dan Saran}

Faktor pertimbangan utama dalam melakukan seleksi metoda untuk mengontrol HAB species adalah efektivitas, toksisitas, biaya dan cara aplikasinya. Distribusi Ulva sp. hampir dapat ditemukan di seluruh perairan dunia sehingga peluang untuk menganalisa berbagai bahan aktif algicidal yang dimiliki sebagai terobosan baru bagi pengembangan eksplorasi bioteknologi sumber daya perairan. Berdasarkan karakteristik tersebut, Ulva sp. sangat potensial sebagai biokontrol untuk HAB species, dimana bahan aktif asam $\alpha$-linolenik dari Ulva sp. mampu menekan pertumbuhan HAB species.

\section{Daftar Pustaka}

Alamsjah MA, Ishibashi F, Kitamura H, Fujita Y (2006) The effectiveness of Ulva fasciata and $U$. pertusa (Ulvales, Chlorophyta) as algicidal substances on harmful algal bloom species. Aquacult. Sci. 54: 325-334

Ikawa M (2004) Algal polyunsaturated fatty acids and effects on plankton ecology and other organisms. UNH Center Freswat. Biol. Res. 6: 17-44.

Jeong JH, Jin HJ, Sohn CH, Suh KH, Hong YK (2000) Algicidal activity of the seaweed Corallina pilulifera against red tide microalgae. J. Appl. Phycol. 12: 37-43.

Kakisawa H, Asari F, Kusumi T, Toma T, Sakurai T, Oohusa T, Hara Y, Chiharai M (1988) An allelopathic fatty acid from the brown alga Cladosiphon okamuranus. Phytochem. 27: 731-735.

Kogteva GS, Bezuglov VV (1998) Unsaturated fatty acids as endogenous bioregulators. Biochem. (Moscow) 63: 6-15.
Murata H, Sakai T, Endo M, Kuroki A, Kimura M, Kumanda K (1989) Screening of removal agents of a red tide plankton Chattonella marina with special reference to the ability of the free radicals derived from the hydrogen peroxyde and polyunsaturated fatty acids. Nippon Suisan Gakkaishi 55: 1075-1082.

Oda T, Ishimatsu A, Shimada M, Takeshita S, Muramatsu T (1992) Oxygen-radicalmediated toxic effects of the red tide flagellate Chattonella marina on Vibrio alginolyticus. Mar. Biol. 112: 505-509.

Sargent JR, Parkes RJ, Mueller-Harvey I, Henderson J (1987) Lipid biomarkers in marine ecology. In Sleigh MA (ed) Microbes in the sea. Ellis Horwood, Chichester, United Kingdom, 119-138.

Sellem F, Pesando D, Bodennec G, Abed AE, Girard JP (2000) Toxic effects of Gymnodinium $c f$. mikimotoi unsaturated fatty acids to gametes and embryos of the sea urchin Paracentrotus lividus. Water Res. 34: 550-556.

Smit AJ (2004) Medicinal and pharmaceutical uses of seaweed natural products: A review. J. Appl. Phycol. 16: 245-262.

Suzuki M, Wakana I, Denboh T, Tatewaki M (1996) An allelopathic polyunsaturated fatty acid from red algae. Phytochem. 43: 63-65.

Suzuki Y, Takabayashi T, Kawaguchi T, Matsunaga K (1998) Isolation of an allelopathic substance from the crustose coralline algae, Litophyllum spp., and its effect on the brown alga, Laminaria religiosa Miyabe (Phaeophyta). J. Exp. Mar. Biol. Ecol. 225: 69-77. 